\title{
Revisitando a Técnica de Eletroconvulsoterapia no Contexto da Reforma Psiquiátrica Brasileira
}

Rediscussing the technique of electroconvulsotherapy in the context of the brazilian psychiatric reform movement

Maura Lima Bezerra e Silva Universidade Vale do Acaraú-PE

Marcus Tulio Caldas Universidade Católica de Pernambuco

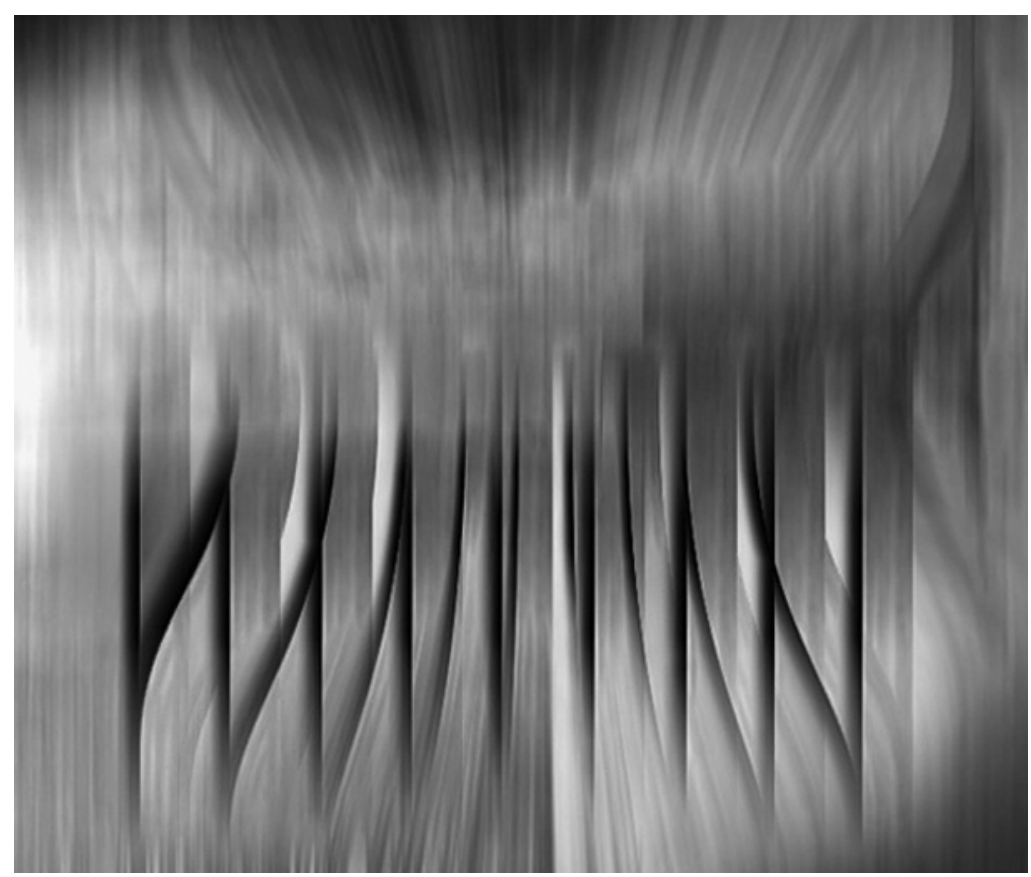


Resumo: A técnica de eletroconvulsoterapia é uma modalidade interventiva da psiquiatria, inaugurada na década de 30 e utilizada ininterruptamente até hoje. A discussão que envolve essa técnica é bastante polêmica, e não porta uma reflexão dialógica entre os campos de saberes afins a ela. Foi proposta do presente estudo realizar uma leitura teórica da técnica, a partir do conjunto teórico-prático do campo da saúde mental, tendo como referência as orientações éticas do Movimento de Reforma Psiquiátrica, intencionando discutir a sua coerência para as práticas de cuidado nesse campo. Problematizar e recomplexificar o tema foi o objetivo geral deste artigo, alcançado através de uma revisão bibliográfica do assunto. Foram identificadas pontes entre a proposta da técnica de ECT e as concepções que embasaram a assistência manicomial/hospitalocêntrica, e, por isso, questionamos a sua coerência para o campo interventivo contemporâneo da saúde mental, que se propõe a dar seguimento às desconstruções do paradigma clássico da psiquiatria.

Palavras-chave: Eletroconvulsoterapia. Psiquiatria. Reforma psiquiátrica. Práticas de saúde.

\begin{abstract}
The eletroconvulsotherapy technique is a psychiatric intervention modality inaugurated in the 30's and used uninterruptedly so far. The discussion related to this technique is very controversial and does not involve a dialogic reflection among its related areas of knowledge. The present study intended to undertake a theoretical interpretation of the technique through mental health theoretical and practical knowledge, based on the ethical orientations of the Brazilian Psychiatric Reform Movement, in order to discuss its coherence as a care giving practice. Therefore, the main objective of this paper was to question and to recomplex the subject, what was achieved through a bibliographical study on the theme. We identified links between the proposal of the ECT technique and the conceptions that support the asylum/hospital care and, therefore, we question its coherence in the mental health contemporary intervention area, which intends to continue the deconstruction of the classic paradigm in psychiatry.
\end{abstract}

Keywords: Eletroconvulsotherapy. Psychiatry. Psychiatric reform. Care giving practices.

Falar em eletroconvulsoterapia ou eletrochoque, como comumente é conhecida a técnica, é envolver-se sempre em uma discussão bastante polêmica. No âmbito acadêmico, alguns se posicionam em sua defesa, alegando ser essa uma técnica efetiva e de bons resultados no tocante à eliminação de sintomas psiquiátricos. Outros trazem para a discussão elementos de uma ética que parecem problematizar esses argumentos.

Ao sermos expostos ao primeiro conjunto de argumentos, ou seja, àqueles que se colocam em defesa dessa técnica por sua suposta efetividade e pela segurança de seus resultados, alguns questionamentos foram suscitados: é efetiva para quem? Que parâmetro é adotado para se dizer que essa técnica traz bons resultados? O que estava se conceituando como benéfico? Por que essa técnica, que é tão defendida por um grupo de profissionais, é, ao mesmo tempo, alvo de tantas críticas por outro grupo igualmente especializado?

Possíveis respostas a tais questões nos parecem estar em aberto, uma vez que esse debate, além de quase ausente, quando 
"...a pesquisa vincula pensamento e ação, ou seja, nada pode ser intelectualmente um problema se não tiver sido, em primeiro lugar, um problema da vida prática" (1994, p. 17).

Minayo viabilizado, é tratado a partir de uma única perspectiva. Representantes das ciências naturais parecem não considerar outras dimensões (psicológicas e sociais) que aludam à complexidade do sujeito; representantes das ciências humanas demonstram certa aversão ao assunto, abordando-o, muitas vezes, como algo do passado, já extinto, pelo menos ideologicamente. Possíveis diálogos entre essas diferentes posturas não costumam ocorrer, de modo que o tema tende a continuar ou no silêncio ou abordado nos extremos de diferentes posturas epistemológicas.

A eletroconvulsoterapia, enquanto modalidade interventiva do campo médico psiquiátrico, está, entretanto, bastante viva, sem, no entanto, ser refletida numa postura de diálogo entre os campos dos saberes científicos afins a ela. Há cinco anos, o Conselho Federal de Medicina a normatizou através da resolução no 1.640/2002. Quisemos aqui fazer acender esse debate nos propondo, à luz do conjunto de conhecimentos da reforma psiquiátrica, realizar uma leitura da técnica de ECT, intencionando, a partir dos questionamentos já levantados, analisar a coerência do uso dessa técnica, tendo por base o conjunto teórico-prático acumulado no campo da saúde mental.

Sabe-se, todavia, que a área da saúde mental comporta hoje vários posicionamentos e modos de intervenção possíveis. Adotam-se aqui aqueles que estão vinculados a uma proposta de questionamento dos paradigmas clássicos da psiquiatria, os que comportam uma compreensão do humano norteada pelos princípios ético-epistemológicos da reforma psiquiátrica.

Para essa reflexão, nós nos colocamos três questões norteadoras: quais elementos epistemológicos oferecem subsídios de sustentação para a prática do ECT? Ou ainda, em que base epistemológica a técnica de ECT se apóia? Tomando como base o lastro teórico da saúde mental filiada à proposta da reforma, que leitura pode ser feita da técnica?

Problematizar e recomplexificar o tema a partir de uma postura dialógica norteada pelas concepções de base do Movimento de Reforma Psiquiátrica foi o objetivo geral do estudo. Através de uma revisão bibliográfica do assunto, foi aberta uma discussão teórica, uma tentativa de diálogo entre diferentes posturas epistemológicas no que tange, sobretudo, à concepção de sujeito, ao sofrimento psíquico e à assistência/cuidado.

Tal intenção não se justifica, entretanto, por motivos puramente teóricos, mas sobretudo pela dimensão prática e ética na qual estão envolvidas pessoas, usuários de ECT. Afinal, como lembra Minayo, "...a pesquisa vincula pensamento e ação, ou seja, nada pode ser intelectualmente um problema se não tiver sido, em primeiro lugar, um problema da vida prática" (1994, p. 17).

\section{A técnica de eletroconvulsoterapia: uma apresentação}

\section{Histórico}

Foi a malarioterapia, método de choque pela febre proposto por Juareg (1917), que abriu o circuito de tratamentos biológicos em psiquiatria. A prática de provocar convulsões com vistas à melhora de sintomas psiquiátricos teve sua origem no pensamento de Meduna (1933). Esse autor, ao perceber que era incomum ocorrer crises convulsivas em pacientes esquizofrênicos, ou seja, uma rara 
sobreposição entre psicoses e convulsões, e observar que a recuperação desses esquizofrênicos era facilitada ao apresentarem um episódio epiléptico - lançou a hipótese de que a epilepsia seria capaz de antagonizar a esquizofrenia, e sugeriu um antagonismo biológico entre as convulsões da epilepsia e os delírios psicóticos. Tal crença tinha apoio na idéia de que "...uma condição psiquiátrica poderia ser alterada por uma doença sistêmica" (Fink, 2007, p. 206).

A partir dessa premissa, abriu-se uma série de tratamentos biológicos: a prática de transfusão de sangue de pessoas epilépticas para esquizofrênicas, a administração de drogas convulsivantes, a insulinoterapia 1, a lobotomia ${ }^{2}$, e, finalmente, a eletroconvulsoterapia.

Foi em 1938, com Cerletti e Bini, que o método de ECT começou a ser utilizado. Todavia, a teoria de Meduna, que deu sustentação às práticas convulsivantes, foi posteriormente contestada, pois "...a comunidade científica reconheceu que a teoria da incompatibilidade biológica entre as convulsões e a esquizofrenia não era verdadeira" (Sabbatini, 2001, p. 6).

Embora essa prática tenha sido amplamente utilizada desde sua origem, nas décadas de 60 e 70, sua popularidade diminuiu bastante. Pensa-se em duas razões para tal declínio: o advento e a utilização de neurolépticos mais efetivos e a crescente movimentação antagônica ao ECT em função do uso indevido e punitivo da técnica. "Pacientes problemáticos e rebeldes recebiam várias sessões de choque por dia, muitas vezes, sem sedação ou imobilização muscular adequadas" (Sabbatini, 2001, p. 9).

Apesar de ter perdido muito de sua popularidade e credibilidade durante o referido momento, nos últimos quinze anos, a prática de ECT voltou a ganhar destaque. "Relatos de pacientes resistentes à farmacoterapia, na década de 80, levaram os médicos a retomarem o uso clínico da ECT" (Fink, 2007, p. 207). Nesse ínterim, mudanças técnicas haviam aprimorado a segurança e a eficácia da ECT, fazendo a sua utilização ser ampliada para além dos quadros psicóticos. Segundo nos informa Fink (2007), atualmente, a ECT é utilizada de forma ampla em todo o mundo.

Segundo o artigo 9o da Resolução do Conselho Federal de Medicina (no 1.640/2002), "A eletroconvulsoterapia tem indicações precisas e específicas, não se tratando, por conseguinte, de terapêutica de exceção" (p. 15, grifos nossos), o que pode ser traduzido como um incentivo do referido órgão para sua utilização.

Respeitando o devido preparo para a eletroconvulsoterapia..., pode-se afirmar que esse é um tratamento extremamente seguro para os pacientes, comportando muitas vezes menos risco que a utilização de psicotrópicos; mais ainda, em determinadas condições, a eletroconvulsoterapia tem eficácia claramente superior aos medicamentos correntemente utilizados. (Del Porto, 2006, p. 18)

\section{Principais parâmetros da técnica}

Pode-se definir a eletroconvulsoterapia (ECT) como "...a utilização de descargas repetitivas eletricamente induzidas nos neurônios no sistema nervoso central..." (Hales, 1992, p. 622) para tratamento. Essa técnica está situada no conjunto de métodos físicos de tratamento em psiquiatria e tem o objetivo de produzir alterações no comportamento ou ainda a finalidade de obter melhora em sintomas psiquiátricos. De acordo com Fink 
"A rapidez e a eficácia da ECT podem fazer dela a primeira indicação para pacientes com depressões graves e grande risco de suicídio, ou mesmo para certos casos de mania aguda que, pela gravidade dos riscos, requeira pronta intervenção" (Del Porto, 2006, p. 18).
(2007), pode-se dizer que a indução repetida de convulsões é o evento principal na eficácia do tratamento. Porém, o autor adverte que as convulsões alteram sintomas individuais ou, no máximo, grupo de sintomas, não funcionando como resolutor de transtornos ou doenças (Fink, 2007).

Existe considerável variabilidade entre os clínicos a respeito da extensão em que o ECT deve ser utilizado em primeira instância ou ser considerado apenas quando outros recursos já se mostraram ineficazes: "A rapidez e a eficácia da ECT podem fazer dela a primeira indicação para pacientes com depressões graves e grande risco de suicídio, ou mesmo para certos casos de mania aguda que, pela gravidade dos riscos, requeira pronta intervenção" (Del Porto, 2006, p. 18).

Busnello (1995) elege alguns critérios para a indicação de ECT como forma de tratamento. Para o autor, deve-se escolher a ECT como tratamento de primeira escolha nos casos em que há necessidade de melhora rápida, quando os riscos de outros tratamentos forem maiores comparados aos da ECT, quando há histórico de boa resposta à ECT em momentos anteriores ou resposta insatisfatória ao uso de psicofármacos, e ainda, quando a pessoa opta por esse tipo de intervenção. A esse respeito, Del Porto (2006) acrescenta que a ECT pode ser mais segura que tratamentos farmacológicos, para os fisicamente debilitados, os idosos e as gestantes, desde que com os devidos cuidado e monitoramento.

Já como tratamento de segunda escolha, Busnello (1995) direciona os casos em que, mesmo na vigência do uso adequado de psicofármacos (quanto à dose e tempo de duração), ocorrer ausência de resposta terapêutica satisfatória, severos ou maiores efeitos colaterais em relação aos da ECT e deterioração do quadro clínico-psiquiátrico.

No que concerne à indicação da ECT, verificou-se alguma divergência entre os autores pesquisados. Há, entretanto, concordância entre um grupo de autores sobre o fato de que o ECT estaria indicado nos casos de: depressão monopolar, na fase maníaca e depressiva do transtorno afetivo bipolar e em alguns tipos de esquizofrenia, especialmente a forma catatônica (Bastos, 2003; Busnello, 1995; Del Porto, 2006; Lawrence, 1980; Resolução № 1.640/2002; Spoerri, 1979; Salzman, 1978). Segundo Fink (2007), a ECT é particularmente efetiva para aliviar transtornos depressivos, embora aponte que ela promove alívio em estados de humor não somente depressivos, mas maníacos, em psicoses diversas e transtornos motores catatônicos.

À parte essa concordância, muitos outros quadros, que divergem de autor para autor, são citados: as psicoses atípicas e reativas, puerperais, casos de delirium tremens, transtornos conversivos, doença de Parkinson, síndrome neuroléptica maligna, convulsões intratáveis, depressão pós-parto, acinesias, pelagra, dor talâmica e dor severa da neuralgia do trigêmeo.

Em relação às contra-indicações, tanto se encontram informações de que nenhuma condição constitui, por si, uma contraindicação absoluta (American Psychiatric Association, 1990), desde que se tomem precauções apropriadas, quanto as que apontam algumas situações contra-indicadas ao uso do ECT.

Para Del Porto (2006), há um conjunto de situações clínicas que requerem cuidados específicos durante a aplicação de ECT, “... 
por implicarem maior risco" (Del Porto, 2006, p. 24). Segundo esse autor, constituem condições que requerem especial avaliação e manejo: situações cardiovasculares instáveis (infarto recente, angina instável, doenças coronarianas, insuficiência cardíaca congestiva), aneurismas ou malformações vasculares que possam se romper devido ao aumento da pressão arterial, condições que acarretem o aumento da pressão intracraniana (tumores e lesões), acidente vascular cerebral recente, algumas condições pulmonares (doença pulmonar obstrutiva crônica, pneumonia, asma não controlada) e condições que impliquem aumento do risco anestésico.

Dentro da corrente que defende a existência de contra-indicações, a descompensação cardíaca, a presença de aneurisma aórtico, os casos de lesões cerebrais e a tuberculose são apontados como os principais excludentes à terapia eletroconvulsiva.

Uma vez estabelecida a indicação clínica da ECT, os usuários deverão passar por uma extensa avaliação clínica. Essa avaliação prévia tem, de acordo com Del Porto (2006), tripla finalidade: avaliar a gravidade do quadro psiquiátrico, a fim de que sejam estudados os efeitos terapêuticos, avaliar as funções cognitivas através de testes neuropsicológicos, em especial a memória, que servirão como ponto de referência para a avaliação dos efeitos colaterais sobre ela, identificar e tratar quaisquer condições clínicas que possam oferecer riscos de maiores efeitos colaterais ou mesmo que contra-indiquem o tratamento.

O exame clínico não pode prescindir, além dos aspectos gerais (registro da pressão arterial, pulso, avaliação das mucosas, hidratação, etc) da palpação do crânio, da ausculta pulmonar e cardíaca, da palpação abdominal e do exame neurológico básico ...A avaliação da dentição do paciente é fator importante... Considerando que a ECT poderá induzir a um aumento transitório da pressão intra-ocular, a história prévia de glaucoma... fará necessária a medida da pressão intra-ocular... Considerando a importância da oxigenação cerebral durante a ECT, a contagem de glóbulos vermelhos, a dosagem de hemoglobina e hematócrito devem sempre preceder o tratamento... Incluímos na avaliação a dosagem de glicemia, creatina, uréia, sódio e potássio... A avaliação da função hepática é sempre requerida, uma vez que os pacientes serão submetidos a anestesia... (Del Porto, 2006, p. 25)

Cumpridos esses requisitos e, complementarmente, realizados uma radiografia do tórax e da espinha dorsal, um eletrocardiograma e um eletroencefalograma e ainda a avaliação pré-anestésica, o usuário estaria apto para o procedimento. No momento anterior à aplicação, o usuário deve estar em jejum, as próteses dentárias e outras devem ser retiradas, a bexiga e o reto devem ser esvaziados e é aplicada ainda uma anestesia, a fim de reduzir a ansiedade da pessoa durante os preparativos. Na hora da sessão, quando já deitado, busca-se proteger o paciente de movimentos extremos na hora da convulsão, que ocasionariam possíveis fraturas, coloca-se na boca um calço depressor da língua ou uma mordaça para se prevenirem mordidas e/ou deslocamentos na mandíbula.

Após a aplicação da corrente e já inconsciente, mesmo quando não apresenta a convulsão, a pessoa não consegue lembrar-se de ter sido submetida ao procedimento, e, “...caso o paciente, após o espasmo elétrico, permaneça aturdido e experimente uma angústia muito penosa, trata-se da crise frustra devido a uma quantidade insuficiente de eletricidade" (Spoerri, 1979, p. 1169). 
Supõe-se que

o cérebro seja privado de energia e do metabolismo oxidativo a

ponto de tornar-

se incapaz de manter sua

função; entretanto, diz-se que "o uso do choque eletroconvulsivo é inteiramente empírico" (Lawrence, 1980, p. 652).
No que diz respeito à freqüência de utilização do ECT, Lawrence (1980) sustenta que a duração do tratamento irá depender dos resultados alcançados e da natureza do distúrbio em questão. Essa é também a postura do Conselho Federal de Medicina, na última Resolução (no 1.640/2002).

Já sobre o mecanismo de ação da ECT, observou-se certa escassez na bibliografia consultada. A maioria dos autores concorda que ainda pouco se sabe acerca desse ponto. Fink (2007) afirma que não há estudos diretos sobre o papel das convulsões, por exemplo, embora se continue acreditando que estão no efeito convulsivo as respostas satisfatórias até então obtidas: "A questão de como as convulsões podem afetar o comportamento estimulou muitas percepções que pontuam a literatura... e nenhuma explica a conexão entre os eventos cerebrais e o comportamento" (Fink, 2007, p. 211).

Supõe-se que o cérebro seja privado de energia e do metabolismo oxidativo a ponto de tornar-se incapaz de manter sua função; entretanto, diz-se que "o uso do choque eletroconvulsivo é inteiramente empírico" (Lawrence, 1980, p. 652).

A esse respeito, pode-se pensar que, se os mecanismos de ação são pouco conhecidos, as possíveis implicações também o seriam. "Não se sabe por quanto tempo ou com que freqüência as convulsões devem ser repetidas nem qual é a melhor maneira de se utilizar um protocolo de manutenção para que os benefícios sejam mantidos" (Fink, 2007, p.209).

No que diz respeito aos efeitos colaterais, os distúrbios de memória são apontados como o principal, embora sejam citados ainda os estados confusionais, a cefaléia e as náuseas. A leitura feita de tais distúrbios, entretanto, varia entre os autores. Busnello (1995) explica que tal distúrbio pode ir desde uma pequena amnésia, passando pelo esquecimento de acontecimentos anteriores ao tratamento (que pode se estender até dois anos antes), esquecimento do período de tratamento, até um déficit permanente. Para Lawrence (1980), esse distúrbio ocasionado pela eletroconvulsoterapia é vivenciado sob forte sentimento de angústia, e pode variar desde uma tendência ao esquecimento de nomes até uma grande confusão. Salzman (1978) coloca que, quanto maior for o número de aplicações, mais tempo leva a recuperação. Segundo o relatório da Associação Brasileira de Psiquiatria, no entanto, “...os efeitos da ECT sobre a memória são transitórios, reversíveis e mínimos, quando comparados aos benefícios trazidos aos pacientes..." (citado por Bastos, 2003, p. 3). Fink (2007) ressalta que esses prejuízos, como assim os chamam, quase sempre são passageiros. "Muito pode ser feito para minimizar esses efeitos, mas parece impossível evitá-los totalmente" (Fink, 2007, p. 209).

\section{A reforma psiquiátrica como propulsora de uma outra forma de considerar as ciências e as suas modalidades interventivas}

O movimento da reforma psiquiátrica traz como tônica a desconstrução e a superação, em termos de teorias e práticas assistenciais, do modelo asilar/ hospitalocêntrico - expresso tanto no manicômio quanto no saber sobre a loucura - e oferece, em sua proposta político-social, subsídios para se encontrar outras formas de conceber o humano, a dita "loucura" ou a doença mental, e, em conseqüência, os modelos clínicos de intervenção, assistência e cuidado.

A lógica de assistência calcada na filosofia manicomial/hospitalocêntrica repousa na concepção de um sujeito fundado nos 
parâmetros da razão universal - expressão mais fina da "natureza humana" (Bezerra, 1992). Esse sujeito, por ser dotado da faculdade da razão, é passível de controle de seus atos, de sua vida e do mundo que o cerca. É alguém disciplinado que atende às regras, normas e pactos sociais, sendo, portanto, um sujeito com condições de se compromissar com a manutenção da ordem social, exatamente através do uso dessa faculdade.

Dentro desse panorama de referências inaugurado com o discurso iluminista do século XVIII, a loucura passa a ser vista como falha da razão, e o louco como alguém alienado daquilo que, ao mesmo tempo, define o humano e lhe dá condição para a vida em sociedade. A razão vai funcionar, portanto, como agente da exclusão da loucura. “...Como ser alienado da sua razão, o louco não era considerado propriamente um sujeito... e não poderia ter discernimento para se apropriar legitimamente de sua liberdade" (Birman, 1992, p.74).

Desse modo representado, o louco, enquanto um furo no desenho de vida pautado na razão, deveria ser extinto, e, enquanto erro da razão, corrigido. "A cura significava resolver o equívoco, voltar a pensar como antes, ou como os outros, os razoáveis" (Corbisier, 1992, p. 10). Sem espaço no universo simbólico, o lugar social reservado para a loucura não poderia ser outro a não ser o da exclusão, do encarceramento e da morte subjetiva.

Essa forma de conceber o sujeito, fundado numa razão universal, e a loucura, como o anverso desse protótipo natural, é o solo epistemológico para a modalidade de assistência clássica, denominada ainda de manicomial/asilar ou hospitalocêntrica. Nessa perspectiva, a noção de assistência ou cuidado se refere a um conjunto de práticas que possuem como finalidade maior a eliminação de sintomas. $\mathrm{O}$ acervo de recursos utilizados durante a história da Medicina mental para alcançar esse fim inclui desde a internação, passando por técnicas de hidroterapia e a administração de psicofármacos, até a aplicação de estímulos elétricos ou o uso de procedimentos cirúrgicos. O importante é utilizar dispositivos que caminhem na direção da correção daquilo que sinaliza "erros" de fabricação subjetiva.

Caracterizados como métodos de exclusão, segregação e violência, predominam nesses serviços as relações de tutela, disciplina e controle, exercidos sob uma modalidade institucional pouco flexível quanto ao poder de contratualidade dos internos. Aliás, autonomia e espaço de contratualização são palavras excludentes à gramática asilar.

Marcado pela constituição da Medicina mental enquanto campo de saber teóricoprático, esse novo desenho de vida para os loucos indica que, "...na modernidade, loucura diga respeito fundamentalmente à psiquiatria" (Birman, 1982, p. 5, citado por Amarante, 1995, p. 24). Entretanto, ao importar o modelo da Medicina biológica, a psiquiatria adota uma prática que se limita a "...observar e descrever os distúrbios nervosos, intencionando um conhecimento objetivo do homem" (Amarante, 1995, p. 2). Com isso, a Medicina mental opta pela naturalização de seu objeto "...através do processo de objetivação, ou seja, o de fazer surgir a objetividade da doença, com a exclusão da subjetividade e a construção de generalidades" (Camargo, Guedes, \& Nogueira, 2006, p. 1095).

Tal operação vai traduzir a constituição de um pensamento de natureza organicista e, a um só tempo, reducionista. As doenças 
“...não são vistas como construções, ficções criadas e categorizadas por homens, mas efetivamente como entidades que existem" (Camargo et al., 2006, p. 1096) e que, pela realidade de suas existências, acabam por virtualizar o paciente.

Com a difusão do Movimento de Reforma Psiquiátrica contemporânea, essa forma de conceber a assistência e a dita "loucura" foi, aos poucos, revisitada e redescrita, visando à confecção de novas práticas de cuidado. Visava-se a desconstruir os paradigmas de sustentação da prática manicomial de exclusão e segregação do louco e de sua subjetividade. A esse respeito, Amarante (1992) nos lembra que essa desconstrução não se circunscreve apenas à destruição física dos hospitais psiquiátricos, mas à promoção e à superação de seu aparato, com a ruptura do paradigma que fundamenta e autoriza a instituição psiquiátrica clássica: o paradigma racionalista.

Se no tipo de assistência clássica se colocava o "sujeito entre parênteses" (Basaglia, 1982) para se enxergar quase que exclusivamente a doença, na perspectiva da reforma, buscase colocar a "doença entre parênteses", priorizando o sujeito que adoece e seu sofrimento. O autor comenta que "...o mal da psiquiatria clássica está em haver separado um objeto fictício - a doença - da existência dos pacientes do corpo social..." (Basaglia, 1982, citado por Barros, 1994, p. 191).

A proposta é que o objeto da psiquiatria não mais se reinscreva na doença, mas no sofrimento psíquico ou na "existênciasofrimento" (Rotelli, 1992). Dessa forma, o papel dos profissionais se centra na necessidade de construção de serviços e modalidades interventivas de cuidado que efetivamente superem a lógica manicomial, relacionando o cuidado ao sofrimento, sem objetificá-lo.
Quando se fala em suspender a doença mental, não se incorre no pensamento de negação do adoecimento, mas num “... procedimento epistemológico de suspender o conceito de doença mental enquanto saber produzido pela psiquiatria..." (Basaglia, 1981, p. 309, citado por Amarante, 1992, p. 180), que reduz a complexa problemática subjetiva do sofrimento psíquico a noções categóricas, fruto de seu arranjo epistemológico.

Tal suspensão marca, a um só tempo, tanto a ruptura com esse saber que se apresenta como obstáculo epistemológico quanto a possibilidade da construção de uma outra relação de cuidado com as pessoas enfermas, uma relação que não seja atravessada primeiramente pelo "...diagnóstico, sintoma ou doença ou ainda pelas... incrustações institucionais, sociais e culturais que são impregnadas aos sujeitos objetivados pelo saber e prática psiquiátricas" (Amarante, 1997, p. 180).

No campo da assistência e do cuidado, em conseqüência dessa reorientação, deixa de ser importante que se persiga a idéia racionalista de tratamento enquanto reparação ou devolução de estados de saúde perdidos para, em seu lugar, baseando-se numa ética solidária de inclusão, buscar a emancipação de condições de vida através da invenção de processos de singularização que possam promover novas inscrições subjetivas.

No plano epistemológico, a concepção que suporta essa quebra de paradigmas é a de um sujeito que põe em questão toda e qualquer lógica de causalidade linear e que perde a primazia da razão e do modo de leitura orgânica. Entende-se que o sujeito tem um corpo e que o seu adoecer comporta uma dimensão orgânica, mas, além desse corpo, ele é alguém inscrito dentro de um universo 
social que o socializa, que lhe possibilita trocas, que o situa historicamente e que, a todo tempo, lhe diz quem é e deve ser, a partir dos parâmetros socioculturais de seu tempo.

O sujeito, no entanto, não é apenas portador de um corpo inserido numa dada sociedade, já que ele dá significado a essas experiências, e o faz de modo diferente dos demais sujeitos. Esse é, para Corbisier (1992), o "pantanoso terreno da subjetividade", em que a psiquiatria clássica optou por não adentrar em suas operações objetivadas na noção de doença mental.

A concepção freudiana de sujeito dividido, descentrado, sem essência, ajuda-nos a pensar no humano como um ser de contingência, ausente de "natureza", e portador não de igualdade subjetiva, mas de diferenças. Reconhecer a não essência do sujeito significa, portanto, fazer ceder o dualismo cartesiano por compreensões marcadas por uma indissociabilidade biopsicossocial do sujeito, em sua condição de contingência e possibilidade, sempre plurais.

Essa perspectiva abre uma outra visão de pathos que, oriundo da psicopatologia, descola-se de uma visão tradicional para ser lido como experiência de sofrimento, tal como propõe a psicopatologia fundamental, que busca compreender e discursar, através da escuta, sobre esse sofrer. Tal discurso não se faz pelo viés da descrição e da sistematização das doenças, pois baseia-se “...no pressuposto de que o pathos manifesta uma subjetividade que é capaz, através da narrativa, de transformar a paixão e o assujeitamento numa experiência..." (Berlink, 2003, p. 5).

Lembra-nos Corbisier (1992) que, na concepção freudiana, o delírio, e, porque não dizer, o "sintoma" psíquico, seria uma forma de dar sentido a uma experiência subjetiva conflitiva. O sintoma indica sinais de sofrimento e pode conduzir à enunciação do desejo singular daquele que sofre. Nessa perspectiva, o sofrimento psíquico, do qual o sintoma se faz porta-voz, pode falar de “...uma estratégia de existência diante de problemas colocados para um sujeito que talvez não tenha encontrado palavras ou ações afirmativas para enfrentá-los... um sinal de vida aflito e aturdido, mas um índice de que a condição desejante se mantém..." (Gondar, 2003, p. 16).

Desse modo, o sintoma psíquico seria o meio encontrado pelo sujeito de comunicar um estado de dor psíquica, que reflete, ao mesmo tempo, um corpo e uma dada realidade social. Amparando-nos no pensamento freudiano, somos conduzidos a "...uma crítica fundamental das terapêuticas antidelirantes..., que representam o delírio como desvio da razão e como perda da função subjetiva" (Birman, 1992, p. 87).

Ao recorrer a esse tipo de leitura do sujeito, pensa-se que é ampliada a concepção de assistência e cuidado, fazendo relativizar o peso normativo da razão frente a outros valores, como a aceitação da diferença, a inclusão, o respeito à pluralidade de formas existenciais e à liberdade, de fato. Com a reforma, o sofrimento psíquico é entendido como algo que necessita de cuidado, não de correção. A noção de existência-sofrimento “...reorienta o objetivo da psiquiatria, passando da 'cura' para a produção de vida, de sociabilidade, de subjetividades. A terapia deixa de ser entendida como perseguição da solução-cura" (Rotelli \& Amarante, 1992, p. 52).

A noção de doença mental, tão cara ao discurso da psiquiatria clássica, ganha para 
"...De doença mental para a existênciasofrimento, o

fenômeno psíquico deixa de ser um mal obscuro que afeta as pessoas e passa a ser um fenômeno complexo, histórico, um estado de nãoequilíbrio..." (Rotelli \& Amarante, 1992,

p. 52). a ética da reforma uma outra apresentação. “...De doença mental para a existênciasofrimento, o fenômeno psíquico deixa de ser um mal obscuro que afeta as pessoas e passa a ser um fenômeno complexo, histórico, um estado de não-equilíbrio..." (Rotelli \& Amarante, 1992, p. 52).

Todo modo de intervenção é pautado num campo filosófico-epistemológico, pois se sustenta numa visão de mundo, de homem, de saúde e doença, de assistência e cuidado; ressignificar o sintoma e a experiência de sofrimento implica, portanto, a partir dessa ótica, assumir uma outra forma de se intervir, já que o sintoma, na condição de possibilidade de fazer emergir o desejo singular, pede um lugar de escuta, de continência, não de contenção. "Sendo assim, não há o que ser corrigido... Não há o que ser abolido" (Corbisier, 1992, p. 10), mas há o que ser escutado e acolhido como forma de receber o sofrimento e poder facilitar a sua transformação numa experiência integrada para quem o vivencia. Corbisier (1992) considera, desse modo, a escuta da diferença como um dos modos antimanicomiais de lidar com a loucura.

Deixa de ser legítima, portanto, a adoção de dispositivos voltados apenas para a eliminação de sintomas. As intervenções devem procurar cuidar do sofrimento do outro, idéia que implica - mais do que atender ou tratar acolher e abrigar a dor psíquico-existencial. Essa autora nos sinaliza para a urgência em não se responder rapidamente às queixas sintomatológicas, e sim para a urgência de se mediar crises com perguntas e tentativas de falas que "...muitas vezes, diluem a urgência de uma resposta-tampão, transformando-as em pedido de ajuda..." (Corbisier, 1992, p. 12).

As intervenções, acompanhando a complexidade da experiência do adoecer, devem visar, além do aspecto sintomatológico, à inscrição ou reinscrição da pessoa no exercício da cidadania e no vínculo com a vida social. Nesse sentido, a crise é um evento de vida, e não mais uma fratura na continuidade da existência, e, embora possa se repetir, pode, a cada novo momento, ser atravessada, devendo-se procurar colocá-la “...no interior de uma série de nexos que são capazes de tornála compreensível..." (Dell 'Acqua \& Mezzina, 2005, p. 164), recebendo-a, acolhendo-a em sua singularidade e complexidade, a fim de estabelecer com ela uma relação de cuidados e de compartilhamento, não de supressão ou erradicação.

Há, portanto, a urgência de se pensar em "...projetos de invenção de novas formas de cuidado em assistência psiquiátrica" (Amarante, 1992, p. 11) que efetivamente substituam a lógica manicomial e assumam o compromisso ético da diferença como meta a ser cotidianamente buscada na superação dos vícios de intervenções de cunho asilar.

Tais projetos devem ter como preocupação primária o outro que demanda ajuda, não permitindo que filiações e categorias teóricas rígidas passem na frente do contato com esse outro em sua experiência de dor e sofrimento. A autonomia deve ser buscada e estimulada, assim como o respeito às individualidades em suas diferenças; o controle e a disciplinaridade, enquanto metas asilares, devem, portanto, ceder lugar à expressão do singular, sob pena de outra vez, em nome de uma suposta normalidade, fazer sucumbir diferentes formas subjetivas em favor da norma subjetiva padrão. É a demanda complexa do usuário o norte pelo qual se deve percorrer a assistência ao sofrimento. Esses são aspectos aqui adotados como critérios de validade ou de coerência de um dispositivo terapêutico dentro da filosofia de assistência da reforma. 
Permanecer com modalidades de assistência permeadas pela noção de que cuidar é apenas produzir a erradicação de sintomas psíquicos tem, para esse novo referencial, o significado de um desserviço ao usuário, já que se estará combatendo exatamente a estratégia que lhe permitia lidar com sua dor psíquica, denunciar o seu sofrimento decorrente dessa dor e solicitar ajuda.

Não escutar o sintoma de modo complexo é, portanto, não permitir que ele encontre lugar no mundo daquele que sofre, é não permitir que ele possa apontar novos modos de singularização, novas possibilidades de existência para aquele sujeito; é, ainda, contribuir para a sua cristalização e criar uma situação propícia à sua cronificação; é, em última instância, impossibilitar que esse sujeito, ao seu modo, possa integrar esse sofrer para transformá-lo numa experiência. Isso significa não cuidar do usuário de acordo com a ética da reforma psiquiátrica, mas permanecer a repetir o que Birman (1992) chama do incansável mito das origens, no qual uma prática se apresenta modulada de outros instrumentos, sejam físicos, sejam tecnológicos, sejam humanos, mas ligada, em sua natureza, ao projeto do alienismo, fundante das práticas asilares. "A instituição inventada... passa a ser uma multiplicidade de serviços e circuitos que buscam superar cotidianamente os vícios dos saberes completos, os vícios das instituições totalitárias, para produzir trocas sociais, possibilidades e subjetividades sempre novas e plurais" (Amarante, 1992, p. 54).

O processo de desconstrução a que convida a forma de assistência antimanicomial parece interminável, e, mesmo tendo avançado enquanto postura ideológica sociopolítica, no campo da assistência, na relação dos técnicos com a dita "loucura", na forma de cuidar, parece que algumas questões ainda permanecem: "o que fazer com os loucos"? "Como lidar com a 'loucura'"?

Sabemos que a figura do louco perde, ao longo da História, a condição de sujeitocidadão, e nós temos, a partir da cartilha da reforma, de estar atentos ao modo de exercer o cuidado, questionando-nos a respeito do que estamos fazendo pelo não ofuscamento da diversidade subjetiva, pelo resgate da cidadania e da autonomia e pela reinscrição social.

Se, do ponto de vista teórico, percebe-se um avanço na desconstrução do aparato manicomial clássico, na prática, onde as dificuldades acontecem, muitas intervenções caminham ainda na direção dessa lógica. Por isso, não podemos afirmar que "...o manicômio esteja morto, ele persiste, às vezes mais limpo, modernizado ou humanizado" (Barros, 1994, p. 175).

Identifica-se, por um lado, uma dificuldade de pôr em prática o discurso antimanicomial tão divulgado, e, por outro, um caminhar oscilante que, ao mesmo tempo em que ensaia novas formas de cuidado, tende a repetir alguns passos da trilha asilar devido à herança cultural que carrega.

E esse tem sido aparentemente o caminho pelo qual propostas de reformulação da assistência psiquiátrica se desfiguram em experiências de miniaturarização e tentaculização do espaço asilar. Tal como uma sombra, essas propostas freqüentemente trazem - atrás dos novos modelos de intervenção - mecanismos mais sutis de controle e de regulação normativizante. (Bezerra, 1992, p. 113).

É compartilhando esse tipo de preocupação que se questiona: seria a técnica de ECT mais uma das "sombras" do modelo assistencial 
clássico? Será que essa técnica é coerente com a proposta de assistência da reforma? Pode-se pensar que tanto a forma de concebê-la quanto a sua utilização não mais atendem a mecanismos, ainda que sutis, de controle e regulação? E ainda, tomando como base epistemológica a perspectiva de questionamento da lógica hospitalocêntrica, de que forma se pode fazer uma leitura dessa técnica? Dentro desse contexto, ela poderia ser considerada um dispositivo terapêutico válido?

\section{Questões sensíveis e possíveis lacunas da técnica de ECT}

Retomando o debate técnico da ECT a partir da perspectiva dos autores citados, identificamos algumas problematizações, lacunas e contradições.

O primeiro ponto sensível diz respeito à percepção de certa imprecisão quanto às indicações e contra-indicações. Através do que é explicitado nas indicações, sinalizase a possibilidade de que grande parte dos transtornos psiquiátricos e outras situações clínicas sejam, em potencial, passíveis de recebimento da técnica. Pensa-se que tais nuanças de imprecisão falem de uma abrangência que pode remeter a uma utilização pouco delimitada e criteriosa da técnica e mais susceptível à obscuridade na compreensão de sua finalidade.

Um outro ponto sensível, que chega a assumir o caráter de uma contradição, diz respeito ao reconhecimento e à defesa da eficácia dessa técnica, por um lado, e, por outro, ao seu uso cada vez mais limitado e restrito. Afirma-se que, embora a eletroconvulsoterapia tenha sua importância no cenário terapêutico, ela está cada vez mais em desuso nesse cenário diante, por exemplo, da freqüência de utilização dos psicofármacos e das psicoterapias na prática psiquiátrica. Os psicofármacos estariam em condições de atualmente funcionar de forma mais eficaz, e são, ainda, mais econômicos. "Em grande número de casos, sua administração (a dos psicofármacos) evita dano temporário permanente para o tecido cerebral e sua função" (Lawrence, 1980, p. 649).

Até então, não se pensa em nenhuma contradição; afinal, espera-se que, no itinerário de evolução científica, novas tecnologias, mais modernas e aprimoradas e menos bruscas, assumam o cenário das intervenções. Na Itália, por exemplo, que se constituiu em berço e fonte de inspiração para a Reforma Psiquiátrica Brasileira, a técnica de ECT foi erradicada em alguns setores do país no campo da assistência em saúde mental.

O consenso a esse respeito, entretanto, parece distante. Para Bastos (2003), a ECT não deveria ser utilizada como terapêutica de exceção ou como medida de último recurso. Ao contrário disso, Pitliuk (2001) coloca que: “a ECT não é o único método, mesmo para os casos gravíssimos. É muito raro precisar indicá-la" (p. 2). Desse modo, questionase: por que uma técnica "consagrada mundialmente" é "raramente" utilizada? Por que não pode ser largamente usada, assim como os psicofármacos? E ainda, o que leva o Ministério da Saúde, por exemplo, a avaliar, através do Programa Nacional de Avaliação dos Serviços Hospitalares (PNASH), o uso de ECT como algo negativo para a instituição hospitalar que a realiza ou a prescreve?

A respeito da avaliação do PNASH, que tem como meta a proposição de melhorias dirigidas aos serviços hospitalares, a fim de que estes possam atender aos padrões de qualidade estabelecidos pelo Ministério 
da Saúde, percebe-se que o recurso da eletroconvulsoterapia não é considerado uma modalidade terapêutica de larga validade. Ao contrário, dentro dos parâmetros estabelecidos por esse programa (quanto ao ECT), vê-se que a excelência de uma instituição hospitalar é conferida somente quando a mesma nem realiza o procedimento, nem o prescreve. E, para receber o conceito "bom", é preciso realizá-la ou prescrevêla excepcionalmente, de acordo com critérios clínicos precisos. Vê-se que, para um grupo de profissionais, a técnica de ECT é considerada um método fácil, eficaz e seguro, e é, ao mesmo tempo, em sua prática de utilização, quando não evitada por outro grupo igualmente especializado ou pela regulação do Ministério da Saúde, secundária ao uso dos psicofármacos, ou ainda utilizada somente como último recurso. É nesse ponto que brota uma contradição. Desse modo, pensamos: por que a técnica de ECT é revestida dessa contradição dentro de seu próprio campo de defesa médico-psiquiátrico? E mais, como entender as orientações do Ministério da Saúde, como órgão maior, regulador das políticas nesse âmbito, frente ao posicionamento do Conselho Federal de Medicina em defesa da técnica? Na ausência de possíveis considerações que pudessem dar conta desses questionamentos em nosso percurso investigativo, os não ditos prevaleceram sobre o explicitado, enunciando, como lacuna, uma argumentação pouco clara e de natureza contraditória.

\section{Lançando as bases para uma outra leitura da técnica}

Busnello (1995), ao abordar a técnica de ECT, faz um paralelo com a cardiologia, que também se utiliza de estímulos elétricos em algumas situações emergenciais, como, por exemplo, em casos de reanimação de alguém com parada cardíaca. Fazendo essa associação, considera injusto que só em relação à psiquiatria o uso dos estímulos elétricos tenha recebido um estigma social na comunidade científica. Ao refletirmos sobre o pensamento do autor, pensamos que o que fundamenta a associação feita entre a cardiologia e a psiquiatria, nesse caso, parece remeter a uma comparação entre órgãos, entre o coração e o representante corpóreo do psiquismo: o cérebro. O que fica implícito na colocação é o destaque dado ao aparato biológico que legitima e justifica as intervenções, ao mesmo tempo em que parece desconsiderar a indissolubilidade entre corpo e mente e a conseqüente imersão do corpo no universo da subjetividade.

Não levar esse aspecto em consideração é não ver que o usuário de ECT recebe tais estímulos elétricos porque se apresenta em estado de intenso sofrimento psíquico, e não em razão de um órgão que não está funcionando bem e que necessita ser corrigido. Aliás, tamanho é o destaque dado por esse discurso à dimensão orgânico-cerebral do sujeito que, além de parecer imprimir uma marca organicista, acaba por solicitar não somente o esvaziamento da bexiga e do reto (a ser realizado imediatamente antes do procedimento de ECT) e a retirada das próteses dentárias do usuário, mas também o esvaziamento e a retirada de algo muito mais peculiar e ao mesmo tempo irremovível - seu universo de subjetividade.

Além disso, referir-se a um sentimento de injustiça parece, ainda, um posicionamento que ignora as formas de utilização punitiva, de controle e ameaça, a serviço das quais a prática de ECT esteve fortemente vinculada em um dado momento da História.

Para Busnello (1995), entretanto, tais marcas e preconceitos são fruto de divulgações 
Ao sofrimento psíquico, à contenção

física, o leito, os psicofármacos e os estímulos elétricos,

ou seja, a forma de assistência, se confunde com a idéia de tratamento, que parece ter um fim comum: conseguir de alguma

forma eliminar os sintomas psíquicos, expressão de um

"descarrilamento", talvez, do eixo da razão e/ou da normalidade orgânico-cerebral. equivocadas da imprensa, que, ao lançar a técnica de ECT sob holofotes para a sociedade, fez com que alguns aspectos na relação médico-paciente/familiares, como a formalização e o fornecimento de esclarecimentos, precisassem ser modificados. Nesse sentido, supomos que as questões relativas à contratualidade, como o procedimento explícito entre médico e paciente, passam a ser vistas como elementos importantes quando pressões externas parecem ameaçar a prática médicopsiquiátrica.

A mesma lógica de raciocínio conduzida por noções organicistas foi observada em Fink (2007), que, ao abordar o problema dos efeitos colaterais ocasionados pela ECT, sugere que devemos considerar "... os impactos da ECT sobre a memória imediata comparáveis à perda de sangue em cirurgias...", afirmando que seria "...tão irracional rejeitar a ECT devido aos impactos previstos sobre a memória quanto seria desconsiderar a cirurgia pelo sangramento que causa" (Fink, 2007, p. 209). E, nesse sentido, a estigmatização da ECT constitui, para ele, “...episódio de desperdício na história da Medicina" (Fink, 2007, p. 212).

A partir dessas considerações, traçamos um desenho epistemológico que parece dar suporte ao campo de defesa da técnica de ECT. Do ponto de vista da concepção de sujeito, parece que se lida com a idéia de um sujeito essencialmente orgânico, sem dimensão subjetiva e social, pelo menos não em um sentido relevante para considerar o sujeito "adoecido" um sujeito epistêmico e perfeito para as intervenções tecnológicas da ciência, que pode deixar de sentir forte doses de angústia frente à utilização de bons psicofármacos e até mesmo tornar-se assintomático através do uso de recursos científico-tecnológicos.
Ao sofrimento psíquico, à contenção física, o leito, os psicofármacos e os estímulos elétricos, ou seja, a forma de assistência, se confunde com a idéia de tratamento, que parece ter um fim comum: conseguir de alguma forma eliminar os sintomas psíquicos, expressão de um "descarrilamento", talvez, do eixo da razão e/ou da normalidade orgânicocerebral.

Uma vez eleito o corpo e os órgãos como objeto, a doença, enquanto expressão do não funcionamento desse corpo neuroquímico, passa ser o foco para o qual se voltam as intervenções corretivas. A noção adotada de que bom resultado e efetividade são sinônimos de ausência de sintoma, e a suposição de que não há sofrimento para aqueles que se submetem ao procedimento pelo argumento de não se lembrarem, servem como exemplos dessa forma de conceber o sofrimento psíquico e a assistência que aqui se identificou. Assintomáticos, sim, mas, como questiona Corbisier (1992), melhores do que o quê?

Tomando-se distância dessa ética da eficácia e adotando valores trazidos pela reforma, baseados numa ética complexa do humano, teremos que pensar se a utilização dessa técnica se propõe a trabalhar sob a ótica de melhor qualidade de vida para o usuário, se estimula sua autonomia, se está preocupada com a reinscrição do usuário em seu contexto social, o que the possibilita o exercício de cidadania, se não tolhe seu movimento singular, se está a serviço do bem- estar biopsicossocial. Entretanto, não foi o que se conseguiu ler, como preocupação relevante, nesse passeio bibliográfico.

O grande problema parece que se circunscreve ao destaque dado à doença, na naturalização a ela conferida, enquanto categoria separada 
de quem a vivencia. Entender a experiência de sofrimento psíquico como doença, apenas, e não como uma tentativa de dar sentido a uma experiência subjetiva conflitiva é o que autoriza a noção de tratamento enquanto via de correção e não de escuta que possa dar sentido e possibilidades de integração de tal experiência.

Pensando nas modalidades interventivas como tecnologias que devem estar a serviço de seus usuários, torna-se difícil conceber ajuda e melhor qualidade de vida dentro de uma perspectiva tradicional, que visa basicamente a alterações ou à eliminação de sintomas psiquiátricos. Passar do objetivo da cura para a produção de vida, de sociabilidades e de subjetividades plurais e mais livres em suas expressões de singularidade - meta das práticas de cuidado orientadas pelo discurso da reforma - é necessariamente ampliar a forma de compreender o humano e a dor psíquica, relativizando ou mesmo abandonando os parâmetros da racionalidade, que vê o sintoma como algo a ser erradicado.

\section{Um outro olhar sobre a ténica de ECT (considerações finais)}

Diante da proposição desses pontos de reflexão, sugere-se uma leitura da técnica de ECT na complexidade que ela comporta, que se coloca além de um debate orgânico, com possíveis considerações de natureza histórica, psicológica, social, política e ética.

Diz-se que o ECT permanece o baluarte da psiquiatria moderna: seguro, fácil e eficiente. Entretanto, pensando na técnica com base no lastro teórico da reforma, levantam-se alguns questionamentos: será que é possível realmente falar em facilidade num procedimento como o da ECT? E a segurança, de qual perspectiva se parte?
Talvez possivelmente do baixo percentual de morte biológica, embora não consensual (1 em cada 25.000 casos / 1 em cada 10.000). Tal assertiva parece desconsiderar os fortes sentimentos de angústia com os quais os usuários de ECT se deparam antes e depois das aplicações, os quais remetem, entre outras coisas, a um estado de medo e insegurança. E mais, será que podemos falar apenas em morte biológica? Nesse sentido, ter-se-ia que atentar para a qualidade de morte subjetiva, a "mortificação do eu" (Goffman, 1961).

Diríamos que essa técnica seria válida ou coerente, dentro da leitura que aqui se propõe, se pudéssemos visualizar em sua proposta de intervenção a desconstrução em relação ao aparato epistemológico-prático manicomial. Isso implicaria não eleger a suposta doença como o objeto exclusivo de intervenção, e sim, o sofrimento psíquico e sua relação com o social, não conceber um sujeito puramente orgânico, fruto da separação cartesiana, mas lidar com a noção biopsicossocial em sua perspectiva de não essência, mas de contingência, de pluralidade subjetiva, entender o sofrimento psíquico não como um sintoma ou disfunção que pede correção e ajustes, mas como um estado que necessita de cuidado (e isso não exclui a utilização de psicofármacos, nem mesmo de eletroconvulsoterapia) e de escuta, como forma de dar sentido a essa experiência subjetiva, ampliar a noção de cuidado e assistência na medida em que o peso normativo da razão fosse relativizado frente a valores como a aceitação da diferença, a inclusão e o respeito à pluralidade existencial, deixar de percorrer o caminho da suposta cura e da simples eliminação de sintomas, com suas dimensões, nem sempre explícitas, de controle e disciplina, para a busca da produção de vida, de sociabilidade e de subjetividades que possam expressar singularidade. 
Teórica e istemologicamente falando, no entanto, a proposta da técnica em questão parece atender mais a um modelo de continuidade do tipo de assistência calcado na postura de assistência manicomial do que de questionamento e de desconstrução da mesma.
Teórica e epistemologicamente falando, no entanto, a proposta da técnica em questão parece atender mais a um modelo de continuidade do tipo de assistência calcado na postura de assistência manicomial do que de questionamento e de desconstrução da mesma. Portanto, se pararmos a nossa reflexão nesse ponto, isto é, apenas no plano teórico, somos levados a questionar a coerência da técnica no presente contexto das práticas de cuidado orientadas pela reforma, no sentido de que o desenho epistemológico de suporte da mesma parece não ser compatível com o da proposta da reforma psiquiátrica.

É válido ressaltar, entretanto, que o que se afirma no meio psiquiátrico contemporâneo de defesa da técnica é que ela, e, portanto, sua prática de intervenção, muito teria evoluído, sendo inegável o reconhecimento da importância de sua utilização em algumas situações, como nos quadros de depressões profundas e em quadros catatônicos, para citar os mais comuns.
Nesse sentido, reconhece-se, desde já, que um trabalho que pudesse ter como campo de estudo a prática de utilização do ECT teria grande valor no sentido de elucidar e ampliar a condução do pensamento aqui traçado. Verificar o uso que hoje é feito dessa técnica no contexto da saúde mental parece ser fundamental, até mesmo para se poder tratar com mais segurança da questão da sua validade enquanto modalidade terapêutica coerente para o contexto de práticas orientadas pela filosofia da reforma.

Pelo reconhecimento que se tem dos aspectos citados acima e por entender o presente estudo como um recorte bibliográfico, deve ser dito ainda que não se objetivou fechar o pensamento ora desenvolvido em uma postura taxativa e de negatividade em relação à técnica, mas, pelo contrário, abrir um debate sinalizador para novas discussões, partir de uma outra ótica de discussão, ficando as novas inclinações investigativas para estudos futuros.

\section{Maura Lima Bezerra e Silva *}

Professora da Universidade Vale do Acaraú (UVA)

Psicóloga graduada pela Universidade Federal de Pernambuco (UFPE)

Mestre em Psicologia clínica pela Universidade Católica de Pernambuco (UNICAP)

Professora da Faculdade Vale do Ipojuca(FAVIP)

\section{Marcus Tulio Caldas}

Professor da Universidade Católica de Pernambuco (UNICAP)

Psiquiatra graduado pela Universidade Federal Fluminense (UFF)

Doutor em Psicologia pela Universidade de Deusto - Espanha

E-mail: marcus_tulio@uol.com.br

\section{* Endereço para correspondência:}

Rua José Bonifácio, no 1356, bloco D, ap. 601 Torre Cep: 50710-000 - Recife - PE

E-mail:mauralima@ig.com.br 


\section{Referências}

Amarante, P. (1992). Algumas notas nobre a complexidade da loucura e as transformações na assistência psiquiátrica. Revista Terapia Ocupacional, 3, 8-16.

Amarante, P. (1995). Loucos pela vida: a trajetória da reforma psiquiátrica no Brasil. Rio de Janeiro: Fiocruz.

Amarante, P. (1997). Loucura, cultura e subjetividade: conceitos e estratégias, percursos e atores da reforma psiquiátrica brasileira. In S. Fleury (Org.), Saúde e democracia: a luta do CEBES (pp. 163-185). Rio de Janeiro: Lemos Editorial.

Barros, D. (1994). Jardins de Abel: desconstrução do manicômio de Trieste. São Paulo: Universidade de São Paulo/Lemos.

Barros, L. (1998). O eletrochoque e a lei. Oficina de Informações, 1-2. Disponível em: www.fenix.org.br/agenda/artigos/ eletrochoque.htm

Bastos, O. (2003). Eletroconvulsoterapia: diretrizes para o seu uso no Brasil. Jornal do Psiquiatra, (18), 3.

Berlink, M. (2003). Ato médico: descaso com a sociedade, desrespeito com a área de saúde. Jornal do Conselho Federal de Psicologia, n. 26, p. 5.

Bezerra, B. (1992). Cidadania e loucura: um paradoxo. In Amarante \& B. Bezerra (Orgs.), Psiquiatria sem hospício: contribuições ao estudo da reforma psiquiátrica. (pp. 113-126) Rio de Janeiro: Relume-Dumará.

Birman, J. (1992). A cidadania tresloucada: notas introdutórias sobre a cidadania dos doentes mentais. In P. Amarante \& B. Benilton (Orgs.), Psiquiatria sem hospício: contribuições ao estudo da reforma psiquiátrica (pp. 71-90). Rio de Janeiro: Relume- Dumará.

Busnello, E. (1995). Eletroconvulsoterapia - ECT. In J. Taborda \& P. Lima (Orgs.), Rotinas em psiquiatria (pp. 272-279). Porto Alegre: Artes Médicas.

Corbisier, C. (1992). A escuta da diferença na emergência psiquiátrica. In P. Amarante \& B. Bezerra (Orgs.), Psiquiatria sem hospício: contribuições ao estudo da reforma psiquiátrica (pp. 9-15). Rio de Janeiro: Relume-Dumará.

Dell 'Acqua, G., \& Mezzina, R. (2005). Resposta à crise: estratégia e intencionalidade da intervenção no serviço psiquiátrico territorial. In P. Amarante (Org.), Arquivos de saúde mental e atenção psicossocial 2 (pp. 161-194). Rio de Janeiro: Nau.

Del Porto, J. (2006). Atualidades sobre eletroconvulsoterapia. SNC em Foco, 2(2) 16-26.

Fink, M. (2007). Psicobiologia do eletrochoque. In J. Licínio \& M. Wong, Biologia da depressão (pp. 206-213). Porto Alegre: Artmed.
Goffman, E. (1961). Manicômios, prisões e conventos. São Paulo: Perspectiva.

Gondar, J. (2003). Clínica, desejo e política. Cadernos do Espaço Brasileiro de Estudos Psicanalíticos, A Clínica como Prática Política, 3(3), 13-18

Guedes, C., Nogueira, M., \& Camargo, J. R. K. (2006). A subjetividade como anomalia: contribuições epistemológicas para a crítica do modelo biomédico. Ciência e Saúde Coletiva, 11(4), 1093-1103.

Hales, R. (1992). Tratado de psiquiatria. Porto Alegre: Artes Médicas.

Lawrence, K. (1980). Manual de psiquiatria clínica (Vol. 2). Rio de Janeiro: Interamericana.

Minayo, M. (1994). Pesquisa social - teoria, método e criatividade (18a ed.). Petrópolis, RJ: Vozes.

Ministério da Saúde. (2003). Programa Nacional de Avaliação dos Serviços Hospitalares - PNSH. Versão Hospitais Psiquiátricos, Brasília.

Pitliuk, R. (2001). Perguntas sobre eletrochoque ou ECT ou eletroconvulsoterapia. Mental Help - Ajuda on line em psiquiatria e neuropsiquiatria (pp. 1-3). Disponível em: www. mentalhelp.com/eletrochoque.htm

Pitta, A. (1996). Cuidados com o cuidar em saúde mental: estratégias de avaliação. Cadernos do IPUB, (3), 159-169.

Oliveira, E. (2002, julho). CFM normatiza eletroconvulsoterapia. Revista do Conselho Federal de Medicina, (30), 4.

Rotelli, F., \& Amarante, P. (1992). Reformas psiquiátricas na Itália e no Brasil: aspectos históricos e metodológicos. In P. Amarante \& B. Bezerra (Orgs.), Psiquiatria sem hospício: contribuições ao estudo da reforma psiquiátrica. (pp. 41-55). Rio de Janeiro: Relume-Dumará.

Sabbatini, R. (2001). A história da terapia por choque em psiquiatria. Cérebro e Mente (web), 1-11. Disponível em: www. epub.org.Br/cm/n04/historia/shock.htm

Salzman, C. (1978). Eletroconvulsoterapia. In R. Shades (Ed.), Manual de terapêutica psiquiátrica (pp. 101-109). Rio de Janeiro: Atheneu.

Spoerri, T. (1979). Compêndio de psiquiatria. São Paulo: Atheneu. 